\title{
The COVID Pandemic: Selected Work
}

\author{
Therese Jones $^{1} \cdot$ Kathleen Pachucki ${ }^{2}$
}

Published online: 22 February 2021

( ) The Author(s), under exclusive licence to Springer Science+Business Media, LLC part of Springer Nature 2021

\section{FROM THE EDITOR}

Similar to many academic journals, we have received a number of submissions over the past months that directly address the current pandemic. In the early months, we saw an unprecedented number of poetry submissions from physicians who seemed to be turning to verse as a way to memorialize what was happening, to find ways of healing from the devastating number of dying patients, and to capture the exhaustion and anxiety of caring for others day after day without respite.

For this issue, we have selected several critical essays, book reviews, and poems from all of those submissions to mark a sad but hopeful first anniversary of COVID. To our colleagues who have been caring for patients, teaching and mentoring students, and contributing to our understanding and awareness of this crisis, thank you for your resilience and your compassion.

Publisher's Note Springer Nature remains neutral with regard to jurisdictional claims in published maps and institutional affiliations.

Therese Jones

therese.jones@cuanschutz.edu

1 Arts and Humanities in Healthcare Program, Center for Bioethics and Humanities, University of Colorado, Anschutz Medical Campus, 13001 E. 17th Pl, Aurora, CO 80045, USA

2 Salt Lake City, USA 